\title{
EFFECT OF POSTERIOR PERICARDIOTOMY ON POSTOPERATIVE SUPRAVENTRICULAR ARRHYTHMIAS AND LATE PERICARDIAL EFFUSION (POSTERIOR PERICARDIOTOMY)
}

Erkan Kuralay, MD

Ertuğrul Özal, MD

Ufuk Demirkılıç, MD

Harun Tatar, MD
Objective: The aim of this prospective study was to evaluate the effectiveness of posterior pericardiotomy from the point of pericardial effusion related with supraventricular tachycardia and development of delayed posterior cardiac effusions. Materials and methods: This prospective randomized study was carried out in 200 patients undergoing coronary artery bypass surgery in Gülhane Medical Academy Department of Cardiovascular Surgery between June 1996 and June 1997. Patients were divided into 2 groups; each group included 100 patients. Longitudinal incision was made parallel and posterior to the left phrenic nerve, extending from the left inferior pulmonary vein to the diaphragm in group I patients. Posterior pericardiotomy was not done in group II. Results: Atrial fibrillation was developed in 6 patients $(6 \%)$ in group I and in 34 patients $(34 \%)$ in group II $(P=\mathbf{. 0 0 0 0 0 0 7})$. Atrial flutter and other supraventricular arrhythmia prevalence was not statistically significant. Early and late pericardial effusion were developed 54\% and $\mathbf{2 1 \%}$, respectively, in group II, but neither early nor late pericardial effusion were developed in group $I(P=\mathbf{0 0 0 0 1})$. Delayed pericardial tamponade was also significantly lower in group I $(0 \%$ vs $10 \% ; P=$ .001). Conclusion: Posterior pericardiotomy is technically easy to perform and a safe and effective technique that reduces not only the prevalence of early pericardial effusion and related atrial fibrillation but also delayed posterior pericardial effusion and tamponade. (J Thorac Cardiovasc Surg 1999;118:492-5)
P ericardial effusion is commonly seen after coronary artery bypass surgery. It is usually small in amount and inconsequential. However in some cases, pericardial effusion may be circumferential and quite large or it may be regional and located in a strategic area, either of which may impede cardiac filling, reduce cardiac output, and lead to tamponade. ${ }^{1}$ Regional pericardial effusions are often localized posteriorly. Previous reports have dealt with the clinical features and management of this problem and have emphasized the high mortality rates associated with delayed treatment. ${ }^{2-9}$ Supraventricular tachyarrhythmias (SVTs), mainly a form of atrial fibrillation, occur in up to $40 \%$ of patients

From Gülhane Military Medical Academy, Cardiovascular Surgery Department, Ankara, Turkey.

Received for publication Nov 23, 1998; revisions requested Jan 12, 1999; revisions received April 16, 1999; accepted for publication April 28, 1999.

Address for reprints: Erkan Kuralay, MD, Gülhane Lojmanları Pamir Apartment No. 15, Etlik, Ankara, Turkey (06010).

Copyright (C) 1999 by Mosby, Inc.

$0022-5223 / 99 \$ 8.00+0 \quad \mathbf{1 2 / 1 / 9 9 5 9 3}$ undergoing coronary artery bypass grafting $(\mathrm{CABG})^{10-14}$ and, although usually benign, can cause hemodynamic instability, prolong hospital stay, and increase cost, and rarely predispose to a cerebrovascular accident. ${ }^{15}$ Pericardial effusions are incriminated in the development of SVT after CABG. ${ }^{16}$ Posterior pericardiotomy has recently been reported to reduce the prevalence of echocardiographically defined pericardial effusions from $40 \%$ in a control group to $8 \%$ in a pericardiotomy group, with a simultaneous reduction in the prevalence of SVT from $36 \%$ to $8 \% .{ }^{17}$ In this prospective study we tested the effectiveness of posterior pericardiotomy, not only pericardial effusion related SVT but also the development of late posterior cardiac effusions.

\section{Patients and methods}

Between June 1996 and June 1997, 826 coronary artery bypass operations were performed in Gülhane Military Medical Academy (GMMA) Cardiovascular Surgery Department. A total of 169 patients with hyperthyroidism ( $\mathrm{n}=$ $2)$, chronic obstructive pulmonary disease $(n=36)$, renal dysfunction $(n=3)$, left ventricular aneurysm $(n=28)$, severe left ventricular dysfunction $(\mathrm{n}=15)$, and combined valvular heart 
Table I. Patient demography

\begin{tabular}{|c|c|c|c|c|c|c|}
\hline & \multicolumn{2}{|c|}{ Group I $(n=100)$} & \multicolumn{2}{|c|}{ Group II $(n=100)$} & \multirow[b]{2}{*}{$\chi^{2}$} & \multirow[b]{2}{*}{$\mathrm{P}$ value } \\
\hline & Mean $\pm S D$ & $n$ & Mean $\pm S D$ & $n$ & & \\
\hline Female (n) & & 23 & & 27 & 0.43 & $.5^{*}$ \\
\hline Age (y) & $57 \pm 12$ & & $61 \pm 8$ & & & $.06^{\dagger}$ \\
\hline Unstable angina (n) & & 34 & & 28 & 0.84 & $.4^{*}$ \\
\hline Preoperative MI (n) & & 41 & & 35 & 0.76 & $.4^{*}$ \\
\hline Normal LV function (n) & & 57 & & 65 & 1.35 & $.2^{*}$ \\
\hline Distal anastomosis (n) & $2.8 \pm 0.8$ & & $3.1 \pm 0.5$ & & & $.09^{\dagger}$ \\
\hline Crossclamp time (min) & $36 \pm 12$ & & $43 \pm 9$ & & & $.10^{\dagger}$ \\
\hline Total perfusion time (min) & $48 \pm 5$ & & $51 \pm 4$ & & & $.12^{\dagger}$ \\
\hline LITA (n) & & 100 & & 98 & & $.2^{\ddagger}$ \\
\hline RITA (n) & & 16 & & 12 & 0.66 & $.4^{*}$ \\
\hline Radial artery (n) & & 54 & & 45 & 1.62 & $.2^{*}$ \\
\hline Abnormal coagulation profile (n) & & 5 & & 4 & 0.12 & $.7^{*}$ \\
\hline Amount of drainage $(\mathrm{mL})$ & $850 \pm 125$ & & $925 \pm 115$ & & & $0.08^{*}$ \\
\hline
\end{tabular}

$M I$, Myocardial infarction.

${ }^{*} \chi^{2}$ test.

'Independent $t$ test.

†Fisher's exact test.

disease $(n=16)$ were not included in this study. Patients who were receiving beta blocker agents treatment $(n=69)$ were also excluded from the study. This prospective randomized clinical study was performed in the first 200 patients undergoing coronary artery bypass surgery who had not had exclusion criteria. For randomization of the patients, the Table of Random Digits ${ }^{18}$ was used, and posterior pericardiotomy was performed in the patients on the first 100 lines of the table; the second 100 lines were accepted as control group. Longitudinal incision was made parallel and posterior to the left phrenic nerve, extending from the left inferior pulmonary vein to the diaphragm (posterior pericardiotomy) in group I as described in Mulay and coworkers. ${ }^{17}$ Informed consent was obtained from all patients. Posterior pericardiotomy was not performed in group II. Two chest tubes (one in the left pleural cavity and the other in anterior mediastinum) were inserted, and the pericardium was left open anteriorly in both groups. No drain was placed behind the heart to avoid tubeinduced ventricular arrhythmias in both groups. Anesthetic medication and surgical techniques were similar in each group. Cardiopulmonary bypass was established with a roller pump nonpulsatile flow after anticoagulation with heparin (3 $\mathrm{mg} / \mathrm{kg}$ ), and activated clotting time was maintained for more than 480 seconds. Membrane oxygenators (Capiox-E, Terumo Corp, Tokyo, Japan) were used in all cases. Heparin was reversed by protamine $(3.5 \mathrm{mg} / \mathrm{kg})$ at the end of the cardiopulmonary bypass. The left pleural cavity was opened in all patients, and patients with dense adhesion of left lung were excluded. All distal anastomosis was done in a single crossclamp period. The left internal thoracic artery (LITA) was used in all patients. Right internal thoracic artery (RITA) was used in 28 patients; 16 of them were in group I. Patient demography is summarized in Table I. After routine closure of the chest, continuous suction $(10 \mathrm{~mm} \mathrm{Hg})$ was applied to the drains, which were milked and stripped at 30-minute intervals to ensure tube patency. Chest tubes were removed when the drainage was less than $20 \mathrm{~mL} / \mathrm{h}$ for consecutive 4 hours. The presence of pericardial effusion was assessed by 2-dimensional echocardiography, which was performed in postoperative days $3,5,7$, and 10, before discharge, and 1, 3 , 6 , and 12 months after discharge. The presence of pericardial effusion on 2-dimensional echocardiography was assessed with criteria described by Martin and colleagues. ${ }^{19}$ The maximum diastolic separation between pericardium and epicardium was measured at the level of the tip of mitral valve leaflet. Any effusion greater than $1 \mathrm{~cm}$ was considered significant. ${ }^{20}$ Patients were examined echocardiographically after discharge. Patients with posterior effusion were recorded. Late posterior effusions and tamponade were recorded. Electrocardiograms of patients have been monitored for detecting arrhythmias when patients were in the bed, and if needed, we used standard 12-lead electrocardiograms. Although the patients were discharged, we taught the family to monitor radial artery pulses at least 3 times a day. In addition, standard 12-lead electrocardiograms were obtained from all patients when the echocardiographic examinations were performed. Arrhythmias were thought to be persistent and clinically significant when the arrhythmias were longer than 30 minutes; we did not count arrhythmias that lasted less than 30 minutes.

Statistical analysis was performed with SPSS software version 7.0 (SPSS Inc, Chicago, Ill). Clinical data are expressed as the mean \pm the SD. Differences were analyzed with $\chi^{2}$ Fisher's exact test and independent $t$ tests.

\section{Results}

The differences between the 2 treatment groups with regard to age, sex, number of the distal anastomosis, duration of crossclamp, total perfusion time, total vol- 
Table II. Postoperative data

\begin{tabular}{|c|c|c|c|c|}
\hline & $\begin{array}{c}\text { Group I } \\
(n=100)\end{array}$ & $\begin{array}{l}\text { Group II } \\
(n=100)\end{array}$ & $\chi^{2}$ & P value \\
\hline Total arrhythmias & 11 & 40 & 22.13 & $.000002^{*}$ \\
\hline Atrial fibrillation & 6 & 34 & 2450 & $.0000007^{*}$ \\
\hline Atrial flutter & 3 & 5 & & $.4^{\dagger}$ \\
\hline $\begin{array}{l}\text { Supraventricular } \\
\text { tachycardia }\end{array}$ & 2 & 1 & & $.5^{\dagger}$ \\
\hline Pleural effusion & 35 & 29 & 0.83 & $.4^{*}$ \\
\hline $\begin{array}{l}\text { Pulmonary } \\
\text { complication }\end{array}$ & 3 & 2 & & $.5^{\dagger}$ \\
\hline Sternal dehiscence & 1 & 1 & & $.8^{\dagger}$ \\
\hline $\begin{array}{l}\text { Early pericardial } \\
\text { effusion }\end{array}$ & 1 & 54 & 70.45 & $.00000001^{*}$ \\
\hline $\begin{array}{l}\text { Late pericardial } \\
\text { effusion }\end{array}$ & 0 & 21 & 19.18 & $.00001^{*}$ \\
\hline Posterior tamponade & 0 & 10 & 10.53 & $.001^{*}$ \\
\hline Hospital stay (d) & 7 & 8 & 0.07 & $.8^{*}$ \\
\hline
\end{tabular}

ume of drainage, LITA/RITA, radial artery usage, and hospital stay time were not statistically significant (Table I). All SVTs were seen in the first 5 days after the operation. Ventricular arrhythmias were rare. Atrial fibrillation was found in 6 patients in group I and in 34 patients in group II $(P=.0000007)$. Atrial flutter was developed in 3 patients in group I and in 5 patients in group II. There was no significant difference when considering pleural effusion. Re-entubation was required because of respiratory insufficiency in 3 patients in group I and in 2 patients in group II. Sternal dehiscence was developed in one patient in each group; RITA and LITA were used in these patients. There was statistically significant difference in early pericardial effusion (1 vs 54 patients; $P=.0000001$ ). Late pericardial effusion (more than 30 days after operation) was also very common in group II (21 patients). We have not found late posterior pericardial effusion in group I, but in group II we found that $21 \%$ delayed pericardial effusion and $10 \%$ delayed pericardial tamponade $(P=.01)$. Symptomatic delayed posteriorly loculated pericardial effusion required echocardiographically quided pericardiocentesis, as described by Y1lmaz and coworkers ${ }^{25}$ in 6 patients, subxiphoid exploration in 2 patients, and anterolateral thoracotomy in 2 patients. Pericardial tamponade was diagnosed in both the hemodynamic data and the echocardiographic findings in these patients. Early pericardial effusion developed in 1 patient in group I in whom both LITA and RITA were harvested; effusion was on the right side of the heart in early postoperative period. This patient was reopened, and clots around the right atrium were removed. There was no significant difference between 2 groups in hospital stay time ( 7 vs 8 days; $P=.8$ ). Table II gives a summary of the results.

\section{Discussion}

SVTs, mainly form of atrial fibrillation, occur in up to $40 \%$ of patients undergoing CABG. ${ }^{10-14}$ Various causes have been suggested, but no reliable prophylaxis is known. ${ }^{13,14,21}$ Previous reports have demonstrated that patients with pericardial effusion had a higher prevalence of supraventricular arrhythmias. ${ }^{16,22,23}$ After coronary operation, the space anterior to the heart may accommodate fluid and is easily drained from a chest drain; but behind the heart, adhesions between the inferior surface of the heart and the diaphragm may create an enclosed space. Mulay and associates ${ }^{17}$ have demonstrated that posterior pericardiotomy could drain freely into the left pleural space thereby reducing the prevalence of pericardial effusion. They also pointed out that supraventricular arrhythmias are significantly less common in patients who are treated with posterior pericardiotomy $(8 \%)$ than the patients treated conventionally (36\%). Asimakopoulos and coworkers ${ }^{24}$ have shown that posterior pericardiotomy was more effective for pericardial drainage, but they also have shown that atrial fibrillation or SVT prevalence were not significantly reduced (20\%) in comparison with the conventional technique $(26 \%)$. We also did not find any statistically significant difference when considering atrial flutter and SVTs. We wish to point out that such low incidences in the patients in this series will not allow for reliable statistical comparison to obtain valid conclusions, but atrial fibrillation prevalence was significantly lower in the pericardiotomy group $(P=$ .0000007). Asimakopoulos and coworkers ${ }^{24}$ included patients who were receiving beta blockers and who had a poor left ventricle in the preoperative period. But we did not include these patients in our study. They pointed out that pericardiotomy groups have significantly higher blood loss, but we did not find significant blood loss difference between the 2 groups. We think that differences between these studies depend on the studycohort design. Late cardiac tamponade is a rare but serious complication, and it has been estimated to occur in up to $6 \%$ of patients after heart operations. ${ }^{2,5}$ Significant delayed pericardial effusion occurred in $1.11 \%$, and $40 \%$ of these patients have posterior cardiac tamponade. ${ }^{25}$ Posterior pericardiotomy also significantly reduces late pericardial effusion $(P=.00001)$ and late posterior tamponade $(P=.001)$.

Several factors such as patients age, beta blockers, hyperthyroidism, left ventricular aneurysm/aneurys- 
mectomy, additional valve surgical procedures, perioperative myocardial infarction, low cardiac output, renal failure, and respiratory complications influence the development of supraventricular arrhythmias, especially atrial fibrillation. The development of atrial fibrillation cannot depend on a single cause, but posterior pericardiotomy significantly reduces arrhythmias.

\section{Conclusion}

Posterior pericardiotomy is technically easy to perform and is a safe and effective technique that reduces not only the prevalence of early pericardial effusion and related atrial fibrillation but also delayed posterior pericardial effusion and tamponade.

\section{REFERENCES}

1. Chuttani K, Pandian NG, Mohanty PK, Rosenfield K, Schwartz SL, Udelson JE. Left ventricular diastolic collapse: an echocardiographic sign of regional cardiac tamponade. Circulation 1991; 83:1999-2006.

2. Borkon AM, Schaff HV, Gardner TJ, Merrill WH, Brawley RK, Donahoo JS. Diagnosis and management of postoperative pericardial effusion and late cardiac tamponade following open-heart surgery. Ann Thorac Surg 1981;31:512-9.

3. Callahan JA, Seward JB, Tajik J. Cardiac tamponade: pericardiocentesis directed by two-dimensional echocardiography. Mayo Clin Proc 1985;60:344-7.

4. Chuttani K, Tischer MD, Pandian NG, Lee RT, Mohanty PK. Diagnosis of cardiac tamponade after cardiac surgery: relative value of clinical, echocardiographic and hemodynamic signs. Am Heart J 1994;127:913-8.

5. Cujec B, Johnson D, Bharadwaj B. Cardiac tamponade by located pericardial hematoma following open heart surgery: diagnosis by transesophageal echocardiography. Can J Cardiol 1991;7:3740.

6. Engelman RM, Spencer FC, Reed GE, Tice DA. Cardiac tamponade following open-heart surgery. Circulation 1970;41 (suppl):II165-9.

7. Maronas JM, Otero-Coto E, Cafferena JM. Late cardiac tamponade after open heart surgery. J Cardiovasc Surg 1987;28:89-93.

8. Sahni J, Tvert T, Herzfeld T, Brondin LA. Late cardiac tamponade after open heart surgery. Scand J Thorac Cardiovasc Surg 1991;25:63-8.

9. Susini G, Pepi M, Sisillo E, Bortone F, Salvi L, Barbier P. Percutaneous pericardiocentesis versus subxiphoid pericardiotomy in cardiac tamponade due to postoperative pericardial effusion. J Cardiothorac Vasc Anesth 1993;7:178-83.

10. Parker FB, Granier-Hayes C, Bove EL. Supraventricular arrhyth- mias following coronary artery bypass: the effect of preoperative digitalis. J Thorac Cardiovasc Surg 1983;86:594-600.

11. Tyras DH, Stothert JC, Kaiser GL. Supraventricular tachyarrhythmias after coronary artery revascularization: a randomized trial of prophylactic digitalization. J Thorac Cardiovasc Surg 1979;77:310-4.

12. Salazar C, Frishan W, Friedman S. Beta blockade for supraventricular tachycardia post-coronary artery bypass surgery: a propranolol withdrawal syndrome. Angiology 1979;30:816-9.

13. Curzen N, Poole-Wilson P. Atrial tachyarrhythmias and coronary artery bypass surgery patient. Br J Cardiol 1994;1:57-9.

14. Fuller JA, Adams GG, Buxton B. Atrial fibrillation after coronary bypass grafting. J Cardiovasc Surg 1989;19:821-5.

15. Pires LA, Wagshal AB, Lancey R, Huang SK. Arrhythmias and conduction disturbance after coronary artery bypass grafting surgery: epidemiology, management, and prognosis [review]. Am Heart J 1995;129:799-808.

16. Angelini GD, Penny WJ, El-Ghamary F. The incidence and significance of early pericardial effusion after open heart surgery. Eur J Cardiothorac Surg 1987;1:165-8.

17. Mulay A, Kirk AJB, Angelini GD, Wishheart JD, Hutter JA. Posterior pericardiotomy reduces the incidence of supraventricular arrhythmias following coronary artery bypass surgery. Eur $\mathbf{J}$ Cardiothorac Surg 1995;9:150-2.

18. Tull D, Albawn GS. Appendix I. Survey research: a decisional approach. New York: Intext Press Inc; 1973. p. 225.

19. Martin RP, Rakowski H, French J, Popp RL. Localization of pericardial effusion with wide angle phased array echocardiography. Am J Cardiol 1978;42:904-12.

20. D’Cruz A, Dolphin H, Overton G, Pai GM. Pericardial complications of cardiac surgery: emphasis on the diagnostic role of echocardiography. J Card Surg 1992;7:257-8.

21. Frost L, Molgaart H, Christiansen EH, Hjortholm K, Paulsen PK, Thomson PE. Atrial fibrillation and flutter after coronary bypass surgery: epidemiology, risk factors, and preventive trials. Int J Cardiol 1992;36:253-61.

22. Bryan AJ, Anglini GD. Pericardial effusion after open heart surgery. Thorax 1990;45:655-6.

23. Ikaheimo MJ, Huikuri HV, Airaksinen J, Korhonem U, Linnaluoto MK, Tarkka MR, et al. Pericardial effusion after cardiac surgery: incidence relation to the type of surgery, antithrombotic therapy and early coronary bypass graft patency. Am Heart J 1988;116:97-102.

24. Asimakopoulos G, Della-Santa R, Taggart DP. Effects of posterior pericardiotomy on the incidence of atrial fibrillation and chest drainage after coronary revascularization: a prospective randomized trial. J Thorac Cardiovasc Surg 1997;113:797-9.

25. Yılmaz AT, Arslan M, Demirkılıç U, Kuralay E, Özal E, Bingöl $\mathrm{H}$, et al. Late posterior tamponade after open heart surgery. J Cardiovasc Surg 1996;37:615-20. 